\title{
Lipoma of Oral Cavity - A Case Report and Review of Literature
}

\author{
Deepali Prakash Mohite¹, Prakash M. Mohite², Snehal U. Udapure ${ }^{3}$ \\ ${ }^{1,3}$ Department of Oral Pathology and Microbiology, Swargiya Dadasaheb Kalmegh Smruti Dental \\ College and Hospital, Nagpur, Maharashtra, India. ${ }^{2}$ Department of Forensic Medicine and Toxicology, \\ Jawaharlal Nehru Medical College and Hospital, Sawangi (M), Wardha, Maharashtra, India.
}

\section{INTRODUCTION}

Connective tissue neoplasms or soft tissue tumours as they are popularly called are mesenchymal neoplasms that affect any part of the body. They occur frequently in all organs including the head and neck region and the oral cavity is no exception. The frequency of their occurrence contributes to 15 - $20 \%$ of all head and neck neoplasms and neoplasms of oral cavity form 1 - $4 \%$ of the reported lesions, 1,2 representing 2.2 $\%$ of all lipomas. ${ }^{3}$ In a study by Moreno SE et al. in 2016 the most frequently affected sites were the buccal mucosa followed by the lips, tongue, palate, and other areas of the oral cavity. ${ }^{4}$ Here we are documenting a case occurring in the buccal mucosa.

\section{PRESENTATION OF CASE}

A 43-year-old male reported to the department with the complaint of swelling and growth on the right cheek (buccal mucosa) region. History of presenting illness revealed that the swelling / growth was approximately $0.5 \times 0.5 \mathrm{~cm}$ at the time of initial observation, 6 months ago, which had increased gradually and had acquired the present size. The swelling was not associated with constant pain, but there was occasional pain with some discomfort while talking and chewing. (Figure 1) Extraoral examination revealed no alteration of vertical or horizontal symmetry. On intraoral examination, a single, arch-shaped, sessile growth was noted on the right buccal mucosa almost at the level of the occlusal plane, which measured approximately 1.5 $\times 1.5 \mathrm{~cm}$ in diameter. It was well-circumscribed, and the surface was smooth. The colour of the growth was similar to that of the adjacent normal mucosa. There was no discharge in the form of pus or blood from the swelling and the surface was not ulcerated. Palpatory findings revealed that the consistency of the swelling was soft and the margins were smooth and there was no fixity to underlying deeper structures though the swelling was slightly compressible and was non-tender.
Corresponding Author: Dr. Prakash M. Mohite, Department of Forensic Medicine, Jawaharlal Nehru Medical College, Datta Meghe Institute of Medical Sciences, Wardha, Maharashtra, India.

E-mail:drprakashmohite@rediffmail.com

DOI: $10.14260 / \mathrm{jemds} / 2021 / 580$

How to Cite This Article:

Mohite DP, Mohite PM, Udapure SU. Lipoma of oral cavity - a case report and review of literature. J Evolution Med Dent Sci 2021;10(33):2851-2853, DOI: $10.14260 / \mathrm{jemds} / 2021 / 580$

Submission 11-05-2021,

Peer Review 09-07-2021,

Acceptance 16-07-2021,

Published 16-08-2021.

Copyright (c) 2021 Deepali Prakash Mohite et al. This is an open access article distributed under Creative Commons Attribution License [Attribution 4.0 International (CC BY 4.0)] 


\section{CLINICAL DIAGNOSIS}

Fibroma

\section{DIFFERENTIAL DIAGNOSIS}

Lipoma, Mucoceles, Epidermoid Cyst, other adipocytic tumours, Metastatic diseases, Hematoma, Sarcoidosis, Infections, Subcutaneous tumours, Vasculitis nodules, and Erythema nodosum.

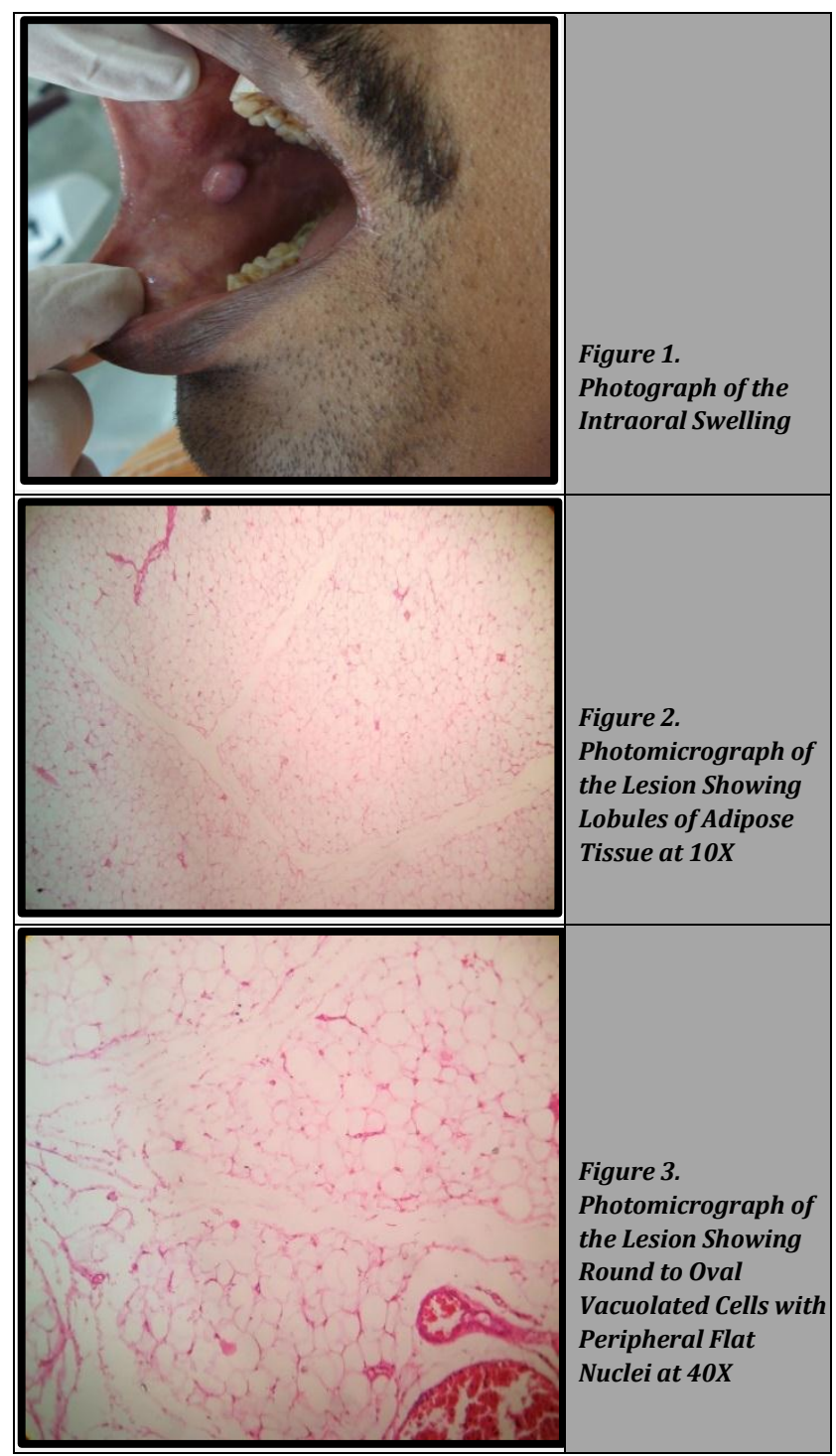

\section{DISCUSSION OF MANAGEMENT}

Treatment involved complete excision of the lesion and histopathological examination. Histopathological features showed intact stratified squamous epithelium of buccal mucosa and connective tissue stroma. Beneath the epithelium was seen an encapsulated tumour composed of large cells which were round to oval in shape. The cytoplasm was vacuolated with nuclei pressed against the peripheral cell membrane, resembling adipocytes, arranged in lobules, and admixed with delicate vasculature. No nuclear atypia, necrosis or mitosis was noted. (Figure 2, Figure 3). By evaluating and assessing both the clinical and histological presentations, a final diagnosis of an intraoral lipoma was arrived at.

\section{DISCUSSION}

Benign mesenchymal tumours of adipose tissue are called lipomas and are often present in the body's cephalic part, trunk, and proximal portion of extremities. The earliest description of oral lipomas was proffered by Roux 5 in the year 1848 in a review of alveolar mass where he mentioned it as "yellow epulis."6

Lipomas are discernible from normal body fat because their lipids are not subject to metabolism which the normal body fat undergoes; additionally, they demonstrate a tendency for uncontrolled proliferation. ${ }^{7}$ These lesions are relatively uncommon in the oral cavity. They account for about $15-20$ $\%$ of all head and neck neoplasms and lipomas of the oral cavity form $1-4 \%$ of benign proliferation.

The term "lipoma" comprises several different entities, including the conventional lipoma and several other histological subtypes with different clinical and histological characteristics. ${ }^{8}$ The aetiology and pathogenesis are still not very clearly understood; though in the earlier literatures ${ }^{9}$ two theories have been proposed - the "hypertrophy theory" and the "metaplastic theory".., 10.11

As per the postulates of the "hypertrophy theory," lipomas occur in the oral cavity because of obesity and inadvertent growth of adipose tissue. However, the occurrence of lipomas at sites devoid of fat could not be explained under this hypothesis. The second theory, "metaplasia theory" states that the differentiation of mesenchymal cells aberrantly into lipoblasts channels the development of lipoma. It has been proposed that trauma and chronic irritation may initiate the proliferation of fatty tissues that can lead to the development of lipoma. ${ }^{9}$ Genetics also appears to contribute to the occurrence of lipomas. $2 \%$ to $3 \%$ of affected patients have been shown to demonstrate multiple lesions on their mucosa through an inherited familial pattern. ${ }^{12}$

A genetic association with chromosome 12 has been established in solitary lipomas due to mutation in the HMGA2 - LPP fusion gene. ${ }^{13,14}$ Lipomas usually occur as solitary lesions but multiple lesions have also been reported. Multiple presentations of lipomas may be seen as a manifestation of the ensuing syndromes:

- Proteus Syndrome

- Dercum disease (adiposis dolorosa)

- Familial multiple lipomatosis

- Benign symmetric lipomatosis (Madelung disease)

- Gardner syndrome.

- Multiple endocrine neoplasia (MEN) type 1.

- Cowden syndrome.

- Bannayan - Riley - Ruvalcaba syndrome (BRRS)

However, in the present case, the patient had a history of mechanical irritation or trauma to the lesion during mastication. The initiation of this lesion due to mechanical trauma was of importance as it ruled out genetic involvement and further assessment of the patient was not needed.

This information was very important to both, the clinician and the patient, to predict prognosis and prevent recurrence 
of the lesion. Complete surgical excision of the lesion is of prime concern as it affects the prognosis and recurrence after treatment. There is an excellent prognosis when benign lipomas are completely excised. Recurrence is not a concern if the excision is completely done though it may recur if surgical removal is incomplete.

\section{CONCLUSIONS}

Intraoral lipomas, though infrequent in occurrence should not be viewed casually and adequate history along with proper excision of the lesion leads to an uneventful postoperative cure.

Financial or other competing interests: None.

Disclosure forms provided by the authors are available with the full text of this article at jemds.com.

\section{REFERENCES}

[1] Kaur R, Kler S, Bhullar A. Intraoral lipoma: report of 3 cases. Dent Res J (Isfahan) 2011;8(1):48-51.

[2] De Sanctis CM, Zara F, Sfasciotti GL. An unusual intraoral lipoma: a case report and literature review. Am J Case Rep 2020;21:e923503.

[3] Kumaraswamy S, Madan N, Keerthi R, et al. Lipomas of the oral cavity: case reports with review of literature. J Maxillofac Oral Surg 2009;8(4):394-7.
[4] Egido-Moreno S, Lozano-Porras AB, Mishra S, et al. Intraoral lipomas: review of literature and report of two clinical cases. J Clin Exp Dent 2016;8(5):e597-603.

[5] On exostosis: there character. Am J Dent Sci 1848;9(1):133-4.

[6] Bakshi SS, Priya M, Coumare VN, et al. A common tumor in an uncommon location: lipoma of the palate. Ann Maxillofac Surg 2015;5(2):237-9.

[7] Tom 0, Tom 0. Lipoma of the cheek presenting with recurrent sialadenitis of the right parotid gland: a case report. J Med Case Reports 2016;10:311.

[8] Pires FR, Souza L, Arruda R, et al. Intraoral soft tissue lipomas: clinicopathological features from 91 cases diagnosed in a single oral pathology service. Med Oral Patol Oral Cir Bucal 2021;26(1):e90-6.

[9] Sharma G, Jain K, Nagpal A, et al. A rare presentation of lipoma on mandibular mucogingival junction. J Indian Soc Periodontol 2016;20(2):199-202.

[10] Gupta TKD. Tumors and tumor-like conditions of the adipose tissue. Curr Probl Surg 1970:1-60.

[11] Alharbi AS. Intraoral lipoma of the cheek-a case report with a one-year follow-up and review of literature. Cureus 2020;12(9):e10537.

[12] Barisella M, Giannini L, Piazza C. From head and neck lipoma to liposarcoma: a wide spectrum of differential diagnoses and their therapeutic implications. Curr Opin Otolaryngol Head Neck Surg 2020;28(2):136-43.

[13] Panagopoulos I, Gorunova L, Agostini A, et al. Fusion of the HMGA2 and C9orf92 genes in myolipoma with $\mathrm{t}(9 ; 12)(\mathrm{p} 22 ; \mathrm{q} 14)$. Diagn Pathol 2016;11:22.

[14] Kolb L, Yarrarapu SNS, Ameer MA, et al. Lipoma. Treasure Island (FL): StatPearls Publishing 2021. 